\title{
Carotid artery calcific disease management strategies during transcarotid artery revascularization
}

\author{
Estratégias de manejo da calcificação da artéria carótida durante revascularização por \\ via transcarotídea
}

Rafael Demarchi Malgor ${ }^{1}$ (D), Nicolas J. Mouawad ${ }^{2,3}$

\begin{abstract}
How to cite: Malgor RD, Mouawad NJ. Carotid artery calcific disease management strategies during transcarotid artery revascularization. J Vasc Bras. 2021;20:e20200152. https://doi.org/10.1590/1677-5449.210152
\end{abstract}

To the Editors,

Endovascular treatment of carotid artery disease has gone through fast-paced evolution since the advent of balloon angioplasty and stents three decades ago. Nevertheless, it was not until significant improvements in neuroprotection were achieved that carotid artery stenting became a solid contender to the gold standard carotid artery endarterectomy. Embolic protection devices, such as proximal common and/or external carotid artery balloon occlusion devices and internal carotid artery filters paved the way toward a safer and more definitive strategy. The concept of flow reversal in the early 2000s, ${ }^{1}$ initially conceptualized by Juan Parodi, has been refined and has culminated contemporarily in the development of a new flow reversal transcarotid artery revascularization and stenting system. ${ }^{2}$

Carotid artery calcific disease remains a challenge in patients undergoing carotid artery stenting regardless of whether it is done via a transfemoral or transcarotid approach. By far, the most challenging scenario is circumferentially calcified internal carotid artery plaques that can cause inadequate expansion of stents and limited luminal gain despite vigorous pre- and post-dilation of the lesion. ${ }^{3}$ Significant residual stenosis ( $>30 \%)$ and incomplete expansion of the stent can largely compromise the durability of the intervention. ${ }^{4}$ Off-label use of FDA-approved, commercially available devices for treatment of calcific lower extremity peripheral arterial disease can be successfully utilized to facilitate carotid artery stenting when compassionate use can be justified.

The two main strategies use either atherectomy devices or the new intravascular lithotripsy (IVL) balloon.
We have reported both use of orbital atherectomy ${ }^{5}$ and IVL balloon angioplasty ${ }^{6}$ during transcarotid artery revascularization (TCAR) in patients with severe carotid artery calcific disease with success. In patients not suitable for open revascularization, our algorithm is to consider use of orbital atherectomy in patients with heavily calcified, eccentric plaques, reserving the IVL technology to treat patients with circumferentially calcified carotid artery lesions. We recommend that flow reversal be maintained a minute longer than usual during those cases, while keeping systolic blood pressure between 140 and $160 \mathrm{mmHg}$ to create a better arterial-venous gradient in order to ensure removal of a larger amount of calciumbased debris. A further step toward large-scale trials employing both technologies to treat carotid artery calcific disease is warranted.

\section{REFERENCES}

1. Bates MC, Dorros G, Parodi J, Ohki T. Reversal of the direction of internal carotid artery blood flow by occlusion of the common and external carotid arteries in a swine model. Catheter Cardiovasc Interv. 2003;60(2):270-5. http://dx.doi.org/10.1002/ccd.10632. PMid:14517938.

2. Malas MB, Leal Lorenzo Jl, Nejim B, et al. Analysis of the ROADSTER pivotal and extended-access cohorts shows excellent 1-year durability of transcarotid stenting with dynamic flow reversal. J Vasc Surg. 2019;69(6):1786-96. http://dx.doi.org/10.1016/j. jvs.2018.08.179. PMid:30611582.

3. Foin N, Gutierrez-Chico JL, Nakatani S, et al. Incomplete stent apposition causes high shear flow disturbances and delay in neointimal coverage as a function of strut to wall detachment distance: implications for the management of incomplete stent apposition. Circ Cardiovasc Interv. 2014;7(2):180-9. http://dx.doi. org/10.1161/CIRCINTERVENTIONS.113.000931. PMid:24642998.

${ }^{1}$ University of Colorado, Division of Vascular Surgery and Endovascular Therapy, Aurora, CO, United States of America.

${ }^{2}$ McLaren Health System, Division of Vascular \& Endovascular Surgery, Bay Region, Bay City, MI, United States of America.

${ }^{3}$ Michigan State University, Division of Vascular Surgery, East Lansing, MI, United States of America.

Financial support: None.

Conflicts of interest: No conflicts of interest declared concerning the publication of this article.

Submitted: August 11, 2020. Accepted: August 20, 2020.

The study was carried out at University of Colorado, Aurora, CO, United States of America. 
4. Chakhtoura EY, Hobson RW 2nd, Goldstein J, et al. In-stent restenosis after carotid angioplasty-stenting: incidence and management. J Vasc Surg. 2001;33(2):220-5. http://dx.doi.org/10.1067/mva.2001.111880. PMid:11174771.

5. Mouawad NJ. Successful use of adjunctive orbital atherectomy for extensively calcified carotid artery lesions using flow reversal neuroprotection technique. Ann Vasc Surg. 2020;69:449.e1-6. http://dx.doi.org/10.1016/j.avsg.2020.05.016. PMid:32473307.

6. Malgor RD, Rogers K, Malgor EA, Al-Musawi M, Siada S, Jacobs DL. The utilization of intravascular lithotripsy to facilitate transcarotid artery revascularization. J Cardiovasc Surg. 2020;61(6):759-62. PMid:32613822.
Correspondence Rafael Demarchi Malgor University of Colorado, Department of Surgery, Division of Vascular Surgery and Endovascular Therapy

11794-8191

Aurora (CO), United States of America Tel.: +1 (303) 724-2697

E-mail: rafael.malgor@cuanschutz.edu

Author information RDM - Associate professor; Chief, Vascular Surgery fellowship, University of Colorado (CU). NJM - Assistant professor, Michigan State University (MSU); Chief of vascular surgery service, McLaren Health System. 